\title{
Chapter 13 \\ Feelings of Guilt in the Family: The Case of Divorced Parents
}

\author{
Matthijs Kalmijn
}

\begin{abstract}
Guilt is believed to be a common emotion in personal relationships. Few studies, however, have examined if guilt plays a role in the divorce process. The present chapter uses unique nationally representative survey data which included questions on the extent to which parents have feelings of guilt toward their (young or adult) children $(\mathrm{N}=3,203)$. By comparing married and divorced parents while controlling for an elaborate set of control variables, we describe the effect of divorce on guilt. By testing a series of variables that may moderate the divorce effect, we subsequently try to explain why divorce affects guilt. Our findings show that there are significant effects of divorce on the feelings of guilt that parents have toward their children. These effects are stronger when parents have more traditional attitudes toward family issues, in line with moral explanations of guilt. The effects are also stronger when the relationship between the child and parent is stronger, in line with explanations of guilt in terms of altruism.
\end{abstract}

Keywords Divorce · Well-being · Children · Intergenerational relations · Guilt

\subsection{Introduction}

Guilt can be defined as the negative feelings that arise from having done something that is or is perceived to be wrong (Baumeister et al. 1994). Guilt has been considered as one of the primary moral emotions that people have (Tangney et al. 2007) and is seen as an unpleasant feeling that may reduce individual well-being (Kim et al. 2011; O'Connor et al. 1999; Webb et al. 2007). Guilt is not the same as shame; guilt is the awareness that one has done something wrong, shame is the translation of that feeling to one's self-image, i.e., the feeling of not being a good person (Tangney et al. 2007). While guilt applies to a large variety of situations, it has been argued that it occurs especially often in close relationships. People may feel guilty

M. Kalmijn $(\bowtie)$

University of Amsterdam, Amsterdam, The Netherlands

NIDI, The Hague, The Netherlands 
if they have done - or think they have done - harm to a friend, partner, child, parent, or other relative (Baumeister et al. 1994). Guilt is thus not only a moral but also fundamentally a relational phenomenon.

Given these arguments, the concept of guilt should figure prominently in research on family relationships. Few studies on marriage and family, however, have systematically measured guilt (Baumeister et al. 1994). There is some research on the division of domestic and household labor in couple relationships which shows that partners who contribute less than their 'fair' share sometimes experience feelings of guilt (Guerrero et al. 2009). There is also research on the guilt problem that some working mothers experience when combining a demanding professional job with the raising of their children (Guendouzi 2006; Henderson et al. 2016). Some studies have examined the guilt that adult children feel toward their ageing and ill parents (Boll and Filipp 2002; Losada et al. 2018). A recent study showed that adult children's feelings of guilt toward their mother are associated with feelings of ambivalence, with imbalances in support exchange, and with norms of filial responsibility (Kalmijn 2018).

One important case where guilt can arise lies in the divorce process. When only one of the partners takes the initiative for a divorce, there is the obvious feeling of guilt toward the partner (Gray and Cohen Siver 1990; Wallerstein and Kelly 1996). Next to feelings of guilt toward the partner, parents who divorce may feel guilty toward their children. Many studies have shown that there are negative effects of parental divorce on the emotional well-being of children (Amato and Anthony 2014; Fomby and Cherlin 2007). Given the increasing media attention to the problems surrounding divorce, it is plausible that parents are generally aware of such effects. Although it is difficult to assess in an individual case whether one's child suffers as a result of the divorce, if the child has problems after divorce, parents may still feel some responsibility for these problems. Of course, married parents may also have children with difficulties and studies suggest that parents are confronted with guilt problems in such cases as well (Godwin 2004). In the case of parents who divorce, however, children's problems will on average be larger and it is plausible that parents attribute these to some extent to their own decision to divorce. As a result, one would expect that divorced parents experience more feelings of guilt toward their children than married parents.

There is very little research that has tested this hypothesis. One exception is a recent qualitative study from Finland which has documented that feelings of guilt toward children are common among divorced parents and more common than feelings of guilt toward the spouse (Kiiski et al. 2013). This study did not make comparisons to married parents, who also may have feelings of guilt toward their children, and did not examine moderators or consequences of guilt. One reason for the scarcity of research on divorce and guilt is that most large-scale surveys which have been used in quantitative research on divorce do not measure guilt.

There are a number of reasons why a study of the link between divorce and guilt is important. First, it is not only important to know if divorce affects guilt, the question is also to what extent and for which parents this is a problem. Representative data are needed to assess the effect size for the association between divorce and guilt 
and quantitative multivariate analyses are needed to study moderating factors. Second, studies on the consequences of divorce for parents tend to focus on more general or more health-related outcomes like life satisfaction and depression (Amato 2000; Leopold and Kalmijn 2016; Williams and Dunne-Bryant 2006). Guilt is perhaps a less 'severe' outcome but it is plausible that guilt feelings play a salient role in people's lives. Third, the case of divorce is an interesting application for the study of guilt because it provides opportunities for testing more general ideas about how guilt develops. As will be discussed below, there are several theories about guilt (Tangney et al. 2007) and these can be tested in part by analyzing the divorce process.

In the present paper, we use a new and large nationally representative survey from the Netherlands in which a module was developed that contained a series of evaluative questions about the parent-child relationship as well as an explicit question on guilt. Guilt was assessed for the feelings respondents have towards the oldest child to make the question more concrete and to allow for including children's characteristics and characteristics of the relationship in the analysis. Because we use a general population survey, the parents and children can be of all ages and the divorce can be recent or not. The role of the age of the child will be studied extensively but the descriptive goal of the paper is to present an estimate of guilt feelings for the average divorced parent vis-à-vis the average married parent. The explanatory goals of the paper will be discussed in the theory section below and will be tested using a series of interaction effects. Note that because we do not have data before and after the divorce, we cannot infer causal effects from our design. We do develop a number of empirical strategies, however, to get more grip on the causal nature of the effects.

\subsection{Theory and Hypotheses}

Our first hypothesis is that parents experience more feelings of guilt toward their children when they are divorced than when they are married (H1). ${ }^{1}$ We argue that there are two mechanisms behind this effect: one based on empathy and one based on morality.

The first mechanism is based on altruism and empathy. According to Tangney, "true interpersonal guilt hinges on an empathic awareness of and response to someone's distress and an awareness of being the cause of that distress. From this perspective, empathy is an essential prerequisite for guilt, at least in earlier developmental stages." (Tangney 1991, p. 600). Evidence from experiments and student samples clearly supports the link between empathy and guilt although the causal direction may go both ways (Joireman 2004; Leith and Baumeister 1998; Tangney 1991). In the case of divorce, the distress consists of the decline in the emotional well-being of the child. It will be clear that not all children are affected

\footnotetext{
${ }^{1}$ When we speak of 'children' in the case of divorce, we refer to the children from the previous marriage and we exclude children who were born in subsequent unions.
} 
by a divorce - there is in fact much heterogeneity in this respect - but on average children of divorced parents have more emotional problems than children of married parents (Amato and Anthony 2014; Fomby and Cherlin 2007). For this to translate into parental guilt, several assumptions are needed. Parents need to attribute the emotional problems that their children experience to the divorce and they need to feel some degree of responsibility for the decision to separate. Research suggests that it is often one of the two partners - and more often the wife - who decides to separate (Kalmijn and Poortman 2006; Sayer et al. 2011). Although this would suggest that mothers feel guiltier than fathers, taking initiative does not per se coincide with being responsible for the problems in a marriage. While we recognize that real or perceived guilt may not be distributed equally within couples, we argue that on average, divorced parents will be more often plagued by feelings of guilt toward their children than married parents.

A second mechanism behind the development of guilt lies in morality. An important theoretical argument in the literature is that guilt is a moral emotion, i.e., a feeling that arises from having broken a moral rule or a social norm (Tangney et al. 2007). The decision to divorce is governed by moral opinions and often disapproved of (Gelissen 2003). Although acceptance of divorce has increased, currently only $60 \%$ of the Dutch population (the population of this study) approves of divorce when parents have children under 12 (Kalmijn and Scherpenzeel 2009). As a result, people who divorce may feel guilty toward their children because they broke this rule. Divorcees may also feel that they were unable to fulfill the role of a 'good parent,' and hence, feel guilty, regardless of what the consequences were for their children.

A direct test of the two mechanisms discussed above is not possible. In a more indirect way, however, there are possibilities to test the relevance of each mechanism. The notion of altruism and empathy can be tested by considering differences in the quality of the relationship with the child. Because there is variation in the strength of the tie that parents have with their children, there will be variation in the degree to which parents are concerned about the harm they may have done to their child. One would thus expect that the effect of divorce on guilt is stronger when the quality of the relationship with the child is stronger (H2). The stronger the tie to the child, the more weight parents will attach to their possible suffering and the guiltier they will feel. Of course, direct measures of the child's well-being would allow for a more direct test of the notion of altruism but this is not possible with the current data.

The second mechanism - the role of norms - can be tested by looking at moderator variables as well. Although the overall public opinion surrounding divorce has become increasingly tolerant over time (Halman \& van Ingen 2015), there still is much variance in such attitudes. Some parents strongly adhere to the symbolic meaning of marriage and disapprove of divorce, whereas other parents may take a more lenient approach and regard divorce as a matter of personal choice. This variation makes it possible to test whether moral mechanisms are involved in the development of guilt. Parents who divorce while being lenient about divorce may not experience moral guilt. In other words, one would expect that the effect of divorce 
on parent's guilt is weaker when parent's own norms about marriage and divorce are more liberal (H3a).

A related but slightly different way to test the moral perspective lies in religiosity. Religiosity is correlated with traditional values about marriage and divorce (Halman and van Ingen 2015) but there is an important conceptual difference between attitudes and religiosity. The former concept addresses the personal norms of a respondent whereas the latter concept also reflects the normative context in which a respondent is embedded. A divorce could be met with disapproval in the church to which one belongs (Kalmijn and van Groenou 2005), which could lead to guilt even when people themselves have liberal personal views on divorce. Hence, we expect that the more often a respondent attends church, the stronger the effects of divorce on guilt ( $\mathrm{H} 3 \mathrm{~b})$.

Next to testing these theoretically derived hypotheses, we look at the role of repartnering. Some repartnered or remarried parents may feel that they 'deserted' their previous family. This would be particularly relevant for divorced fathers since it has been argued that some divorced fathers 'swap families', especially when it is difficult for them to remain attached to their previous children (Manning and Smock 2000). While this would imply greater feelings of guilt among repartnered parents, it is also known that repartnering improves a person's well-being (Dewilde and Uunk 2008) and this could reduce feelings of guilt. We also look at the current age of the child, which reflects both the time that has elapsed since the divorce and the age at which the divorce took place. When children are older, the divorce either was a long time ago and hence, less influential (Amato and Keith 1991), or it happened at an older age when it is also less detrimental for child well-being (Aquilino 1994). Hence, the difference between married and divorced parents in their feelings of guilt will probably be larger when the child is young.

\subsection{Method}

The data were collected as part of a module on family relationships in the LISS panel in the Netherlands (Longitudinal Internet Studies for the Social sciences). The LISS was based on a nationally representative register sample of Dutch households and is a panel study where respondents are asked to fill in questionnaire modules repeatedly (starting in 2007). Respondents are paid to answer questions and have to fill out questions via internet (Computer Assisted Web Interviewing). Respondents without internet or computers were given a PC and free internet access enabling them to participate. The survey was made possible through a grant from the Dutch government. Extensive measures were taken to maximize response for this timeintensive panel study. The result was an initial response rate of $48 \%$ at the household level (Scherpenzeel 2009; Scherpenzeel and Toepoel 2012).

Questions about guilt were included in the family module in 2015, 2016, and 2017. We use all three years and analyze a person-year file using random-effects regression models that accommodate for the clustering of observations within 
persons. We also have yearly measures for all the independent variables. We do not expect clear trends or changes in this short period of time but use all years as repeated observations to increase the reliability of the analysis (Petersen 2004). Averaging would be another option - implying a between-effects regression model but this underutilizes the information that is available (Petersen 2004).

Questions were asked about the relationship with the oldest child and the marital status groups were defined accordingly. From the participants in the family module ( $\mathrm{N}=6098$ ), we selected three groups of respondents: (a) divorced/separated single respondents whose oldest child is a biological child ('single divorced'), (b) married/ cohabiting respondents whose oldest child is the biological child of a previous partner and who were not previously widowed ('repartnered'), ${ }^{2}$ and (c) married/cohabiting respondents who were not previously divorced/separated or widowed and whose oldest child is the biological child of the current partner ('married'). The sample is limited to parents between the ages 18-65. The parents were on average 44 years of age and the children about which they reported were on average 21 . The number of unique respondents observed in any of the three waves was 3203 and of these, 641 unique parents were divorced/separated (either single or repartnered).

\subsubsection{Measures}

Respondents were given a series of statements about the relationship they had with the oldest child (e.g., "I am very fond of my child"). The item on guilt was part of this battery and worded as follows: "I often feel guilty toward my child". Respondents could answer on a scale from 1 ("not applicable to me at all") to 7 ("fully applicable to me"). It should be noted that prior (often clinical) studies typically use more items to measure guilt, sometimes 50 or more (Tilghman-Osborne et al. 2010). Including such a scale was not possible in the LISS panel and would also have been impractical for measuring guilt in one concrete relationship. To the defense of the measure, it can be said that it is correlated in predicted ways with important outcome variables like depression. The correlation between our guilt measure and the short MHI-scale for depressive feelings is $r=.27$ (Rumpf et al. 2001). We also use a measure of feelings of guilt toward the parent's mother, which was measured in the same way as it was for the oldest child. We explain below how we include this aspect of guilt in the analyses.

To measure the quality of the parent-child tie, we use the seven questions that addressed positive or negative sentiments about the child (e.g., "I am very fond of my child", "I am often angry at my child"). The negative items were reversed and the items were combined into a single scale which has a very good reliability $(\alpha=$ .80). This scale and all subsequent scales are constructed by taking the mean across valid items and subsequently standardizing the result $(\mathrm{m}=0, \mathrm{s.d} .=1)$. Details of all items can be found in Table 13.1. The age of the child is included as a linear variable

\footnotetext{
${ }^{2} \mathrm{~A}$ few of these respondents may never have lived together with a partner.
} 
Table 13.1 Descriptive statistics of sample

\begin{tabular}{l|c|c|c|c|l}
\hline & Mean & sd & Min & Max & Count \\
\hline Separated/single & 0.07 & & 0.00 & 1.00 & 7,062 \\
\hline Separated/repartnered & 0.12 & & 0.00 & 1.00 & 7,062 \\
\hline Mother vs father & 0.57 & & 0.00 & 1.00 & 7,062 \\
\hline Age parent & 49.51 & 10.30 & 21.00 & 65.00 & 7,062 \\
\hline Age of child & & & & & 7,062 \\
\hline Age of child (centered) & -0.26 & 11.63 & -20.75 & 28.25 & 7,062 \\
\hline Liberal family values & -0.02 & 1.00 & -4.26 & 1.97 & 5,902 \\
\hline Church attendance & 0.04 & 1.03 & -0.65 & 2.71 & 6,631 \\
\hline Poverty index & -0.06 & 0.92 & -0.47 & 6.06 & 5,699 \\
\hline Working hours & 22.81 & 18.46 & 0 & 80 & 6,234 \\
\hline Agreeableness (z) & 0.04 & 0.99 & -4.63 & 2.29 & 6,393 \\
\hline Extraversion (z) & -0.01 & 1.00 & -3.47 & 2.72 & 6,393 \\
\hline Conscientiousness (z) & 0.16 & 0.94 & -4.10 & 2.55 & 6,393 \\
\hline Drug use & 0.04 & & 0.00 & 1.00 & 5,975 \\
\hline Daily alcohol & 0.18 & & 0.00 & 1.00 & 5,975 \\
\hline Smoker & 0.16 & & 0.00 & 1.00 & 5,975 \\
\hline Quality relation child (z) & 0.05 & 0.96 & -4.84 & 1.02 & 7,062 \\
\hline
\end{tabular}

Source: LISS Family Module 2015, 2016, 2017. Most missing values result from the fact that different variables were obtained from different monthly modules that each have nonresponse

and refers to the current age of the child. To measure traditional versus liberal values, two measures were used. First, we use six attitude statements about marriage and divorce (e.g., "It is perfectly fine for a couple to live together without being married"). These attitudes measure the degree to which a respondent adheres to traditional norms about marriage. The six items were combined into a scale $(\alpha=$ .71) where higher scores indicate more liberal values. Second, we use a measure of the approximate number of church visits, scaled from 0 for never to 52 for weekly (in logged form; 1 was added to make the conversion possible). Religiosity is correlated with liberal values about marriage and divorce $(\mathrm{r}=-.48)$ so we will provide additional tests where religion and attitudes are included separately.

In the absence of longitudinal data, it is especially important to control for possible confounding variables. For this reason, we use a large set of control variables. First, we include three measures of personality. Previous studies have suggested a link between personality and guilt (Fayard et al. 2012) and between personality and divorce (Claxton et al. 2012; Masarik et al. 2013). The LISS data contain the full International Personality Item Pool that was originally developed by Goldberg (Lamers et al. 2012). From this series of items, we constructed three scales: agreeableness $(\alpha=.82)$, extraversion $(\alpha=.88)$, and conscientiousness $(\alpha=.78)$. These items were measured in 2012, 2013, and 2014 and are combined into one static measure to improve the reliability. The reason to make the measure static is that personality is usually believed to be a stable trait. The alpha's were virtually identical in each year (the values above refer to 2012). 
Second, we use measures of health behaviors that reflect things about which a parent may feel guilty and which are known to be associated with divorce (Mortelmans et al. 2011; Waite and Gallagher 2000). Specifically, we include three variables: if the parent smokes, if the parents consume alcohol on a daily basis, and if the parent uses soft- and/or hard drugs. There are not many parents who report drug use (Table 13.1) but enough for testing an effect. Finally, we considered a number of more demographic and socioeconomic characteristics. Of these, we found that poverty is the most relevant in that it correlates with marital status while it also affects guilt. We include an index of five items that measure poverty (e.g., "not being able to pay the rent", "not being able to replace broken appliances"). We also include the number of hours worked and an interaction of hours worked and gender.

Even with a good set of control variables, it is possible that an association between divorce and guilt is not causal in nature. Psychological theories often make the distinction between guilt proneness and guilt experience (Cohen et al. 2012; Fayard et al. 2012). Guilt proneness points to interpersonal differences in feelings of guilt for the same trigger event or situation. Our aim is to assess how divorce affects guilt and we would ideally like to control for divorce proneness if persons who are at risk of divorce would be more guilt prone. To assess this, we use questions on general feelings of guilt and general feelings of shame. The questions were obtained from a more elaborate scale to measure positive and negative affect (Watson et al. 1988). Although not intended to measure guilt or shame specifically, we think these measures provide an interesting way to address the issue of guilt proneness. The items were measured on a 7-point scale and were repeated in 2012, 2013, 2014 and 2017. We average the items across available waves. We regress parents' feelings of guilt on these general measures of guilt and shame and we obtain the residual score to measure the guilt that is specifically targeted toward the child. We replicate our models using this alternative (residualized) guilt measure as an indirect way to control for guilt proneness.

Finally, we examine feelings of guilt toward the mother as one additional outcome to check whether the effect of divorce on guilt is specifically targeted toward the child or a more general feeling of guilt toward family members. Our theories are about the emotional well-being of the child and about the norm of being a good parent, so we would expect the effects on guilt to be present mostly for children and not for feelings of guilt toward one's own parents. This question was asked in the same family module that included the questions about guilt toward children.

Missing values of control variables were imputed using the multiple imputation module in Stata. The dependent variables as well as the divorce variables were used in the procedure but not themselves imputed. 


\subsection{Results}

We start by describing the extent to which parents have feelings of guilt toward their children, regardless of marital status, and how this differs between fathers and mothers. In Figure 13.1, we show how fathers and mothers responded to the question on guilt. The scale ranges from 1 to 7 , where 4 is the neutral score.

We see that a small minority of parents $-15 \%$ of fathers and $17 \%$ of mothers report feelings of guilt toward their oldest child (scores of 5, 6, or 7). Although this number is not high, the main message here is that such feelings are present and not limited to a very small and potentially select group of parents. There is also variation on the positive end of the scale and there is group of people who say they are neutral (about 10\%). To analyze this variable, we use both a linear version where the scale is standardized and a binary version where we contrast the positive scores $(\geq 5)$ to the other scores $(\leq 4)$. The binary approach is the strictest in that it ignores variation on the neutral/left-side of the continuum.

In Table 13.2, we present the random effects regression models where the standardized guilt score is the dependent variable. We include two binary variables for divorced and repartnered parents and use married/cohabiting parents as the reference category. The binary variables for divorce and repartnering both have significant effects on guilt. Single divorced and repartnered parents both have more feelings of guilt than married parents. The effect sizes are moderate: Cohen's d is 0.33 for single divorced parents and 0.39 for repartnered parents. The logit models confirm the findings (Table 13.3). Divorced parents have 2.2 times higher odds (exp (.786)) of reporting guilt feelings than married parents; for repartnered parents, the odds ratio is 2.6.

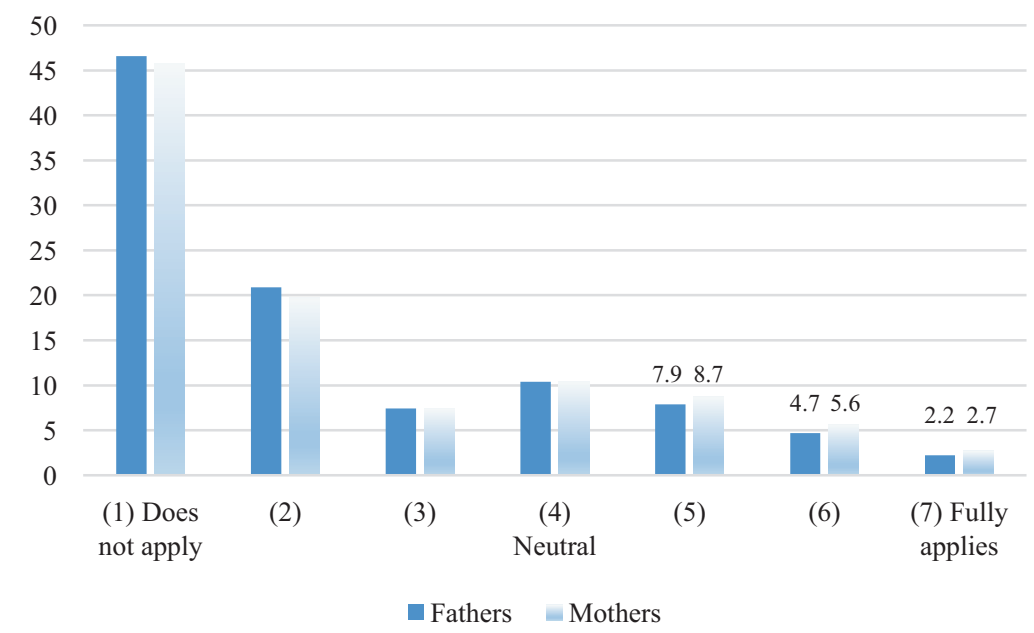

Fig. 13.1 Feelings of guilt toward children 
Table 13.2 Random effects regression of feelings of guilt of parents toward their oldest biological child

\begin{tabular}{|c|c|c|c|c|}
\hline & Model 1 & Model 2 & Model 3 & Model 4 \\
\hline \multirow[t]{2}{*}{ Agreeableness (z) } & -.003 & -.003 & $.042 *$ & -.003 \\
\hline & $(.019)$ & $(.019)$ & $(.018)$ & $(.019)$ \\
\hline \multirow[t]{2}{*}{ Extraversion (z) } & $-.069 *$ & $-.068 *$ & $-.051 *$ & $-.067 *$ \\
\hline & $(.017)$ & $(.017)$ & $(.016)$ & $(.017)$ \\
\hline \multirow[t]{2}{*}{ Conscientiousness (z) } & $-.128 *$ & $-.127 *$ & $-.087 *$ & $-.128 *$ \\
\hline & $(.018)$ & $(.018)$ & $(.016)$ & $(.018)$ \\
\hline \multirow[t]{2}{*}{ Poverty index } & $.055 *$ & $.055 *$ & $.043 *$ & $.054 *$ \\
\hline & $(.015)$ & $(.015)$ & $(.014)$ & $(.015)$ \\
\hline \multirow[t]{2}{*}{ Working hours (z) } & .003 & .005 & .015 & .005 \\
\hline & $(.019)$ & $(.019)$ & $(.018)$ & $(.019)$ \\
\hline \multirow[t]{2}{*}{ Hours x mother } & $.052 *$ & $.051 *$ & $.053 *$ & $.053 *$ \\
\hline & $(.029)$ & $(.029)$ & $(.027)$ & $(.029)$ \\
\hline \multirow[t]{2}{*}{ Drug use } & $.237 *$ & $.234 *$ & $.252 *$ & $.232 *$ \\
\hline & $(.074)$ & $(.074)$ & $(.069)$ & $(.074)$ \\
\hline \multirow[t]{2}{*}{ Daily alcohol } & .058 & .058 & .043 & .058 \\
\hline & $(.040)$ & $(.040)$ & $(.037)$ & $(.040)$ \\
\hline \multirow[t]{2}{*}{ Smoker } & .005 & .004 & -.002 & .009 \\
\hline & $(.042)$ & $(.042)$ & $(.039)$ & $(.042)$ \\
\hline \multirow[t]{2}{*}{ Mother vs father } & $.146 *$ & $.154 *$ & $.149 *$ & $.153 *$ \\
\hline & $(.035)$ & $(.038)$ & $(.032)$ & $(.035)$ \\
\hline \multirow[t]{2}{*}{ Age of child } & $-.017 *$ & $-.017 *$ & $-.018 *$ & $-.017 *$ \\
\hline & $(.001)$ & $(.001)$ & $(.001)$ & $(.001)$ \\
\hline \multirow[t]{2}{*}{ Quality relation child } & & & $-.380 *$ & \\
\hline & & & $(.014)$ & \\
\hline \multirow[t]{2}{*}{ Church attendance } & & & & .000 \\
\hline & & & & $(.016)$ \\
\hline \multirow[t]{2}{*}{ Liberal family values } & & & & .002 \\
\hline & & & & $(.017)$ \\
\hline \multirow[t]{2}{*}{ Separated/single vs married } & $.334 *$ & $.434 *$ & $.262 *$ & $.357 *$ \\
\hline & $(.056)$ & $(.092)$ & $(.052)$ & $(.056)$ \\
\hline \multirow[t]{2}{*}{$\mathrm{x}$ mother } & & -.159 & & \\
\hline & & $(.111)$ & & \\
\hline \multirow[t]{2}{*}{$\mathrm{x}$ age child } & & .000 & & \\
\hline & & $(.005)$ & & \\
\hline \multirow[t]{2}{*}{$\mathrm{x}$ quality relation child } & & & $.096 *$ & \\
\hline & & & $(.038)$ & \\
\hline \multirow[t]{2}{*}{$\mathrm{x}$ church attendance } & & & & -.043 \\
\hline & & & & $(.056)$ \\
\hline \multirow[t]{2}{*}{$\mathrm{x}$ liberal family values } & & & & $-.197 *$ \\
\hline & & & & $(.057)$ \\
\hline Separated/repartnered vs married & $.393 *$ & $.369 *$ & $.335 *$ & $.402 *$ \\
\hline
\end{tabular}


Table 13.2 (continued)

\begin{tabular}{l|l|l|l|l}
\hline & Model 1 & Model 2 & Model 3 & Model 4 \\
\hline & $(.045)$ & $(.069)$ & $(.042)$ & $(.048)$ \\
\hline $\mathrm{x}$ mother & & .036 & & \\
\hline $\mathrm{x}$ age child & & $(.089)$ & & \\
\hline $\mathrm{x}$ quality relation child & & .001 & & \\
\hline & & $(.004)$ & & \\
\hline $\mathrm{x}$ church attendance & & & $.169 *$ & \\
\hline & & & $(.033)$ & \\
\hline $\mathrm{x}$ liberal family values & & & & .030 \\
\hline & & & & $(.055)$ \\
\hline Constant & & & & -.020 \\
\hline & & & & $(.050)$ \\
\hline $\mathrm{N}$ persons & $-.146 *$ & $-.151 *$ & $-.117 *$ & $-.150 *$ \\
\hline $\mathrm{N}$ person-waves & $(.028)$ & $(.030)$ & $(.026)$ & $(.029)$ \\
\hline
\end{tabular}

Source: LISS Family Module 2015, 2016, 2017

Standard errors in parentheses. Multiple imputations. ${ }^{\sim} p<0.10,{ }^{*} p<0.05$

In Model 2, we test whether the effects differ between fathers and mothers and between older and younger children. The gender interaction effects are not significant and not large so we reject ideas about gender differences in the association between divorce and guilt. Interesting is that mothers appear to have somewhat more guilt feelings than fathers but this is true for all marital status categories. Although there is a negative overall effect of the child's age on parents' feelings of guilt, we do not find significant interactions between the divorce variables and the age of the child. This is true in both the linear model (Table 13.3) and in the logit model (Table 13.4).

The control variables have a number of interesting effects. First, there is evidence for the role of personality. Persons who are more extravert and more conscientious have lower feelings of guilt, in line with previous studies. A common interpretation is that persons who are more organized and more planful are believed to make fewer 'mistakes' and therefore have fewer occasions about which they may feel guilty (Fayard et al. 2012). Extraversion is also negatively related to guilt in previous studies and is often explained in terms of the greater cognitive focus of introvert persons on the self (Abe 2004). We find a number of behavioral and situational factors that are also affecting guilt. Parents who experience financial problems report more feelings of guilt. Drug use is positively correlated with guilt, as one would expect, but the number of drug users is small. Smoking and drinking are not associated with guilt. There is no effect of working hours and there is a marginally significant interaction of gender and working hours (the positive effect of working hours on guilt is stronger for mothers). 
Table 13.3 Random effects logit of feelings of guilt of parents toward their oldest biological child

\begin{tabular}{|c|c|c|c|c|}
\hline & Model 1 & Model 2 & Model 3 & Model 4 \\
\hline \multirow[t]{2}{*}{ Agreeableness (z) } & .024 & .025 & $.152 *$ & .018 \\
\hline & $(.072)$ & $(.072)$ & $(.075)$ & $(.073)$ \\
\hline \multirow[t]{2}{*}{ Extraversion (z) } & $-.197 *$ & $-.196 *$ & $-.155 *$ & $-.192 *$ \\
\hline & $(.064)$ & $(.064)$ & $(.066)$ & $(.065)$ \\
\hline \multirow[t]{2}{*}{ Conscientiousness (z) } & $-.355 *$ & $-.352 *$ & $-.251 *$ & $-.352 *$ \\
\hline & $(.068)$ & $(.068)$ & $(.070)$ & $(.068)$ \\
\hline \multirow[t]{2}{*}{ Poverty index } & $.199 *$ & $.201 *$ & $.164 *$ & $.200 *$ \\
\hline & $(.059)$ & $(.059)$ & $(.060)$ & $(.060)$ \\
\hline \multirow[t]{2}{*}{ Working hours (z) } & .070 & .081 & .130 & .073 \\
\hline & $(.083)$ & $(.083)$ & $(.085)$ & $(.083)$ \\
\hline \multirow[t]{2}{*}{ Hours $\mathrm{x}$ mother } & .125 & .112 & .125 & .124 \\
\hline & $(.119)$ & $(.119)$ & $(.122)$ & $(.119)$ \\
\hline \multirow[t]{2}{*}{ Drug use } & $.764 *$ & $.749 *$ & $.850 *$ & $.765 *$ \\
\hline & $(.268)$ & $(.268)$ & $(.275)$ & $(.268)$ \\
\hline \multirow[t]{2}{*}{ Daily alcohol } & .157 & .159 & .147 & .155 \\
\hline & (.164) & $(.163)$ & $(.167)$ & $(.164)$ \\
\hline \multirow[t]{2}{*}{ Smoker } & .183 & .181 & .169 & .186 \\
\hline & $(.162)$ & $(.162)$ & $(.167)$ & $(.163)$ \\
\hline \multirow[t]{2}{*}{ Mother vs father } & $.462 *$ & $.525 *$ & $.514 *$ & $.466 *$ \\
\hline & $(.137)$ & $(.152)$ & $(.142)$ & $(.138)$ \\
\hline \multirow[t]{2}{*}{ Age of child } & $-.040 *$ & $-.042 *$ & $-.049 *$ & $-.040 *$ \\
\hline & $(.005)$ & $(.006)$ & $(.006)$ & $(.005)$ \\
\hline \multirow[t]{2}{*}{ Quality relation child } & & & $-1.045 *$ & \\
\hline & & & $(.072)$ & \\
\hline \multirow[t]{2}{*}{ Church attendance } & & & & .034 \\
\hline & & & & $(.071)$ \\
\hline \multirow[t]{2}{*}{ Liberal family values } & & & & .031 \\
\hline & & & & $(.075)$ \\
\hline \multirow[t]{2}{*}{ Separated/single vs married } & $.786 *$ & $1.101 *$ & $.753 *$ & $.806 *$ \\
\hline & $(.211)$ & $(.333)$ & $(.222)$ & $(.212)$ \\
\hline \multirow[t]{2}{*}{$\mathrm{x}$ mother } & & -.604 & & \\
\hline & & $(.411)$ & & \\
\hline \multirow[t]{2}{*}{$\mathrm{x}$ age child } & & .017 & & \\
\hline & & $(.019)$ & & \\
\hline \multirow[t]{2}{*}{$\mathrm{x}$ quality relation child } & & & $.293 *$ & \\
\hline & & & $(.164)$ & \\
\hline \multirow[t]{2}{*}{$\mathrm{x}$ church attendance } & & & & -.205 \\
\hline & & & & $(.225)$ \\
\hline \multirow[t]{2}{*}{$\mathrm{x}$ liberal family values } & & & & $-.414 *$ \\
\hline & & & & $(.219)$ \\
\hline \multirow[t]{2}{*}{ Separated/repartnered vs married } & $.941 *$ & $.980 *$ & $.946 *$ & $.902 *$ \\
\hline & $(.172)$ & $(.259)$ & $(.178)$ & $(.184)$ \\
\hline
\end{tabular}


Table 13.3 (continued)

\begin{tabular}{l|l|l|l|l}
\hline & Model 1 & Model 2 & Model 3 & Model 4 \\
\hline $\mathrm{x}$ mother & & -.076 & & \\
\hline $\mathrm{x}$ age child & & $(.333)$ & & \\
\hline & & .005 & & \\
\hline $\mathrm{x}$ quality relation child & & $(.015)$ & & \\
\hline & & & $.520 *$ & \\
\hline $\mathrm{x}$ church attendance & & & $(.133)$ & \\
\hline & & & & .099 \\
\hline $\mathrm{x}$ liberal family values & & & & $(.210)$ \\
\hline & & & & .162 \\
\hline Constant & & & & $(.206)$ \\
\hline & $-2.958 *$ & $-2.998 *$ & $-3.107 *$ & $-2.960 *$ \\
\hline $\mathrm{N}$ persons & $(.145)$ & $(.151)$ & $(.153)$ & $(.146)$ \\
\hline $\mathrm{N}$ person-waves & 3203 & 3203 & 3203 & 3203 \\
\hline Sounce: & & 7062 & 7062 & 7062 \\
\hline
\end{tabular}

Source: LISS Family Module 2015, 2016, 2017

Standard errors in parentheses. Multiple imputation. $\sim p<0.10,{ }^{*} p<0.05$

In Model 3, we test our first series of interaction effects that are informative of altruism and empathy. There is a significant interaction of the quality of the parent-child relationship and divorce on guilt. More specifically, we find that the effects of divorce and repartnering are stronger when the relationship with the child is more positive. Both the interaction effects are statistically significant. The effect for single divorced parents becomes $.096 / .262=37 \%$ larger for each standard deviation increase in the quality of the parent-child relationship. For the effect of repartnered parents, the effect becomes $.169 / .335=50 \%$ larger per standard deviation increase in the quality of the parent-child relationship. In the logit model in Table 13.3, we also find significant interactions. These findings are in line with the notion of altruism and empathy since parents should care more for the possible harm that a divorce has done when they hold their children closer.

The hypothesis about social norms is tested in Model 4. We start with individual norms, as reflected in attitudes about marriage and divorce. In line with expectations, we find that the divorce effect is weaker for parents who have more liberal values. In both the linear and the logit model, this interaction only applies to single divorced parents. While these findings are partially in line with our hypothesis, we do not find any significant interaction between divorce and church attendance. The interactions are also very small, both in the linear and in the logit models. In other words, to the extent that morality plays a role, it lies more in a parent's individual norms than in the normative context in which a parent is embedded. In two additional models (not shown), we explore the interactions of church attendance and marriage attitudes one-by-one. We found the same result: there is no significant interaction of divorce and church attendance when the attitude interactions are excluded and there still is a significant interaction of attitudes and divorce and when the church attendance interactions are excluded. 
Table 13.4 Sensitivity regression models of guilt feelings

\begin{tabular}{|c|c|c|c|}
\hline & $\begin{array}{l}\text { (1) Guilt feelings } \\
\text { in general (OLS) }\end{array}$ & $\begin{array}{l}\text { (2) Feelings of guilt toward } \\
\text { the child residualized (re } \\
\text { model) }\end{array}$ & $\begin{array}{l}\text { (3) Feelings of guilt } \\
\text { toward the mother (re } \\
\text { model) }\end{array}$ \\
\hline \multirow{2}{*}{$\begin{array}{l}\text { General shame } \\
\text { feelings (z) }\end{array}$} & $.037 *$ & & \\
\hline & $(.018)$ & & \\
\hline \multirow{2}{*}{$\begin{array}{l}\text { General guilt } \\
\text { feelings (z) }\end{array}$} & $.271 *$ & & \\
\hline & $(.019)$ & & \\
\hline \multirow[t]{2}{*}{ Agreeableness (z) } & & .019 & .011 \\
\hline & & $(.019)$ & $(.023)$ \\
\hline \multirow[t]{2}{*}{ Extraversion (z) } & & $-.057 *$ & -.017 \\
\hline & & $(.017)$ & $(.021)$ \\
\hline \multirow{2}{*}{$\begin{array}{l}\text { Conscientiousness } \\
\text { (z) }\end{array}$} & & $-.067 *$ & $-.144 *$ \\
\hline & & $(.017)$ & $(.021)$ \\
\hline \multirow[t]{2}{*}{ Poverty index } & & $.030 *$ & .031 \\
\hline & & $(.014)$ & $(.019)$ \\
\hline \multirow[t]{2}{*}{ Drug use } & & $.156 *$ & $.248 *$ \\
\hline & & $(.068)$ & $(.092)$ \\
\hline \multirow[t]{2}{*}{ Daily alcohol } & & $.074 *$ & $.115 *$ \\
\hline & & $(.038)$ & $(.051)$ \\
\hline \multirow[t]{2}{*}{ Smoker } & & .003 & -.013 \\
\hline & & $(.042)$ & $(.058)$ \\
\hline \multirow[t]{2}{*}{ Mother vs father } & & $.096 *$ & $.191 *$ \\
\hline & & $(.032)$ & $(.041)$ \\
\hline \multirow[t]{2}{*}{ Age of child } & & $-.016 *$ & $-.005 *$ \\
\hline & & $(.001)$ & $(.002)$ \\
\hline \multirow[t]{2}{*}{ Separated/single } & & $.276 *$ & -.020 \\
\hline & & $(.055)$ & $(.076)$ \\
\hline \multirow{2}{*}{$\begin{array}{l}\text { Separated/ } \\
\text { repartnered }\end{array}$} & & $.374 *$ & -.049 \\
\hline & & $(.045)$ & $(.058)$ \\
\hline \multirow[t]{2}{*}{ Constant } & .003 & $-.119 *$ & $-.215 *$ \\
\hline & $(.012)$ & $(.027)$ & $(.036)$ \\
\hline Observations & 6785 & 6785 & 4477 \\
\hline Adjusted $R^{2}$ & .074 & & \\
\hline
\end{tabular}

Source: LISS Family Module 2015, 2016, 2017

Standard errors in parentheses $p<0.10,{ }^{*} p<0.05$

The final step of the analysis addresses the issue of guilt proneness. For this, we use questions about general feelings of guilt and shame. In the first model of Table 13.4, we regress feelings of guilt toward the child on these more general feelings of guilt and shame. We see positive effects, as one would expect, especially of 
guilt but also of shame. Next, we calculate the residual from this model and use this residual as a dependent variable in a subsequent model. This residual is a measure of guilt toward the child, net of more general feelings of guilt, and can be interpreted as guilt that is not due to interpersonal differences in guilt proneness. The model essentially shows the same effects as were found in Table 13.3. This provides additional evidence that the effects of divorce on guilt are indeed specific to the child.

In the last model of Table 13.4, we use as dependent variable the feelings of guilt that parents have toward their own parents (i.e., their mother). The sample size is smaller since not all parents have a living mother. We see no significant effects of divorce on feelings of guilt toward the mother, showing again that the effect that we find for feelings of guilt toward children is related to normative and empathic concerns about the child. Interesting is that some of the control variables here have even stronger effects. For example, alcohol consumption is associated with feelings of guilt toward the mother than toward the child.

\subsection{Conclusion}

The analysis provided the first systematic piece of evidence that divorced parents have more feelings of guilt toward their children than married parents. The effects are significant, substantial in size, and persist when parents and children are older. Moreover, the effects are not due to a more general tendency to feel guilty or shameful and they are targeted specifically toward the child and not to other primary relations like the mother. In a more general way, these findings point to another way in which a divorce negatively affects well-being. Feelings of guilt are positively associated with indicators of well-being such as depression and may therefore explain why especially parents suffer emotionally from a divorce rather than couples without children who break up (Leopold and Kalmijn 2016).

The analysis has also provided evidence for two important theoretical explanations of the development of guilt. First, we find evidence for the moral dimension of guilt: the notion of being a 'good parent'. The evidence shows that persons who adhere to more traditional norms about marriage and family issues, are more negatively affected by a divorce. There was a significant interaction effect of divorce and marriage attitudes on feelings of guilt. We did not find an interaction of church attendance and divorce, suggesting that personal norms are more relevant for how people feel than the norms in their social context.

Second, we find evidence for the role of altruism and empathy. Guilt arises in part because people empathize with the suffering of others and the case of divorce is a clear example of this, given the evidence that a divorce negatively affects the well-being of children. We show that the effect of divorce on guilt is stronger when the parent-child relationship is stronger. This is evidence of empathy because parents are probably more concerned with the well-being of their children when the relationship is more positive. 
The current study offers initial findings on the link between divorce and guilt and will hopefully inspire further analyses of the problem. One of the puzzles is that the evidence for the moral dimension in the present analysis is weaker than the evidence for the role of altruism. Of the two normative variables, only one had a significant moderator effect and this was only significant for separated parents who did not repartner and not significant for repartnered separated parents. The variable for testing the role of altruism - relationship quality - was significant for both groups of separated parents and also consistent across models (linear and logit). While this suggests more support for the role of altruism and empathy, the indicator for testing this perspective was more indirect. A more direct test of the theory could have been obtained by using measures of children's well-being as possible moderators of the divorce effect. The current data do not have such measures and we think future studies need to be done to examine more systematically how altruism plays a role in the link between divorce and guilt.

One of the more surprising findings in this study lies in the role of the age of the child. One would expect that the effect of divorce on guilt would be more pronounced for parents with younger children but we found a clear divorce gap all through the child's age range (the age-divorce interaction was insignificant). Perhaps one reason for this finding is that in some of the cases where the children are older, the divorce may have been recent. The data do not have exact information on when the divorce occurred - which is one important drawback of our otherwise original data - and this may bias the age interaction downward. Better and more direct tests of age effects could be obtained with information on the timing of divorce.

There are also other ways in which research on the link between divorce and guilt can be advanced. First, it would be important to enrich the measurement. More items could be used to measure guilt in specific relationships and the measures of guilt could be amplified with measures of shame. Many studies have pointed to the conceptual differences between shame and guilt and several studies have also explored the causal relationships between the two. Second, it would be interesting to explore the role of guilt for well-being. There has been debate about whether guilt is important for depression but to the extent that there is an effect, guilt may play a mediating role. The effect of divorce on parents' well-being can be mediated by guilt, but the causal order between guilt and well-being is somewhat ambiguous. Hence, longitudinal designs are needed to disentangle such effects. Third, it would be interesting to generalize the concept of guilt in the case of divorce to the more general notion of 'being a good parent'. There are strong normative expectations in society about what constitutes 'a good parent' and it is important to study how parents respond to such expectations in situations where they are unable - for whatever reason - to meet these expectations. A divorce is an important case in this respect, at least in some conditions, but it is also just one example of a more general phenomenon.

Acknowledgement This chapter benefited from the support of the Centre for Population, Family and Health (CPFH) at the University of Antwerp and the Flemish Agency of In-novation and Entrepreneurship (Grant number: 140069), which enabled Open Access to this chapter. The author's work was funded by the European Research Council under the Horizon 2020 program (ERC grant agreement no. 669334). 


\section{References}

Abe, J. A. (2004). Shame, guilt, and personality judgment. Journal of Research in Personality, 38(2), 85-104. https://doi.org/10.1016/s0092-6566(03)00055-2.

Amato, P. R. (2000). The consequences of divorce for adults and children. Journal of Marriage and the Family, 62(4), 1269-1287.

Amato, P. R., \& Anthony, C. J. (2014). Estimating the effects of parental divorce and death with fixed effects models. Journal of Marriage and Family, 76(2), 370-386. https://doi.org/10.1111/ jomf. 12100 .

Amato, P. R., \& Keith, B. (1991). Parental divorce and adult well-being: A meta-analysis. Journal of Marriage and the Family, 53, 43-58.

Aquilino, W. S. (1994). Later life parental divorce and widowhood: Impact on young adults' assessment of parent-child relations. Journal of Marriage and the Family, 56, 908-922.

Baumeister, R. F., Stillwell, A. M., \& Heatherton, T. F. (1994). Guilt - An interpersonal approach. Psychological Bulletin, 115(2), 243-267. https://doi.org/10.1037//0033-2909.115.2.243.

Boll, T., \& Filipp, S. H. (2002). Prediction of middle-aged offspring's parent-related feelings of guilt. Zeitschrift Fur Entwicklungspsychologie Und Padagogische Psychologie, 34(2), 95-105. https://doi.org/10.1026//0049-8637.34.2.95.

Claxton, A., O'Rourke, N., Smith, J. Z., \& DeLongis, A. (2012). Personality traits and marital satisfaction within enduring relationships: An intra-couple discrepancy approach. Journal of Social and Personal Relationships, 29(3), 375-396. https://doi.org/10.1177/0265407511431183.

Cohen, T. R., Panter, A. T., \& Turan, N. (2012). Guilt proneness and moral character. Current Directions in Psychological Science, 21(5), 355-359. https://doi. org/10.1177/0963721412454874.

Dewilde, C., \& Uunk, W. (2008). Remarriage as a way to overcome the financial consequences of divorce - A test of the economic need hypothesis for European women. European Sociological Review, 24(3), 393-407. https://doi.org/10.1093/esr/jen025.

Fayard, J. V., Roberts, B. W., Robins, R. W., \& Watson, D. (2012). Uncovering the affective core of conscientiousness: The role of self-conscious emotions. Journal of Personality, 80(1), 1-32. https://doi.org/10.1111/j.1467-6494.2011.00720.x.

Fomby, P., \& Cherlin, A. J. (2007). Family instability and child well-being. American Sociological Review, 72, 181-204.

Gelissen, J. P. T. M. (2003). Cross-national differences in public consent to divorce: Effects of cultural, structural and compositional factors. In W. Arts, L. C. J. M. Halman, \& J. A. P. Hagenaars (Eds.), The cultural diversity of European unity: Findings, explanations and reflections from the European values study (pp. 339-370). Leiden: Brill Academic Publishers.

Godwin, S. E. (2004). Managing guilt: The personal responsibility rhetoric among parents of "troubled" teens. Sociological Quarterly, 45(3), 575-596. https://doi.org/10.1111/j.1533-8525.2004. tb02304.x.

Gray, J. D., \& Cohen Siver, R. (1990). Opposite sides of the same coin: Former spouses' divergent perspectives in coping with their divorce. Journal of Personality and Social Psychology, 59, $1180-1191$.

Guendouzi, J. (2006). "The guilt thing": Balancing domestic and professional roles. Journal of Marriage and Family, 68(4), 901-909. https://doi.org/10.1111/j.1741-3737.2006.00303.x.

Guerrero, L. K., La Valley, A. G., \& Farinelli, L. (2009). The experience and expression of anger, guilt, and sadness in marriage: An equity theory explanation. Journal of Social and Personal Relationships, 25(5), 699-724.

Halman, L., \& van Ingen, E. (2015). Secularization and changing moral views: European trends in church attendance and views on homosexuality, divorce, abortion, and euthanasia. European Sociological Review, 31(5), 616-627. https://doi.org/10.1093/esr/jcv064.

Henderson, A., Harmon, S., \& Newman, H. (2016). The price mothers pay, even when they are not buying it: Mental health consequences of idealized motherhood. Sex Roles, 74(11-12), 512-526. https://doi.org/10.1007/s11199-015-0534-5. 
Joireman, J. (2004). Empathy and the self-absorption paradox II: Self-rumination and selfreflection as mediators between shame, guilt, and empathy. Self and Identity, 3(3), 225-238. https://doi.org/10.1080/13576500444000038.

Kalmijn, M. (2018). Guilt in adult mother-child relationships: Connections to intergenerational ambivalence and support. Journals of Gerontology. https://doi.org/10.1093/geronb/gby077.

Kalmijn, M., \& Poortman, A.-R. (2006). His or her divorce? A study of divorce determinants using information on who initiated the divorce. European Sociological Review, 22(3), 201-214.

Kalmijn, M., \& van Groenou, M. B. (2005). Differential effects of divorce on social integration. Journal of Social and Personal Relationships, 22(4), 455-476. https://doi. org/10.1177/026540750504516.

Kalmijn, M., \& Scherpenzeel, A. (2009). Traditionele jongeren en onafhankelijke ouderen. Demos, $25,1-4$

Kiiski, J., Määttä, K., \& Uusiautti, S. (2013). "For better and for worse, or until...”: On divorce and guilt. Journal of Divorce \& Remarriage, 54, 519-536.

Kim, S., Thibodeau, R., \& Jorgensen, R. S. (2011). Shame, guilt, and depressive symptoms: A metaanalytic review. Psychological Bulletin, 137(1), 68-96. https://doi.org/10.1037/a0021466.

Lamers, S. M. A., Westerhof, G. J., Kovacs, V., \& Bohlmeijer, E. T. (2012). Differential relationships in the association of the Big Five personality traits with positive mental health and psychopathology. Journal of Research in Personality, 46(5), 517-524. https://doi.org/10.1016/j. jrp.2012.05.012.

Leith, K. P., \& Baumeister, R. F. (1998). Empathy, shame, guilt, and narratives of interpersonal conflicts: Guilt-prone people are better at perspective taking. Journal of Personality, 66(1), 1-37. https://doi.org/10.1111/1467-6494.00001.

Leopold, T., \& Kalmijn, M. (2016). Is divorce more painful when couples have children? Evidence from long-term panel data on multiple domains of well-being. Demography, 53(6), 1717-1742. https://doi.org/10.1007/s13524-016-0518-2.

Losada, A., Marquez-Gonzalez, M., Vara-Garcia, C., Gallego-Alberto, L., Romero-Moreno, R., \& Pillemer, K. (2018). Ambivalence and guilt feelings: Two relevant variables for understanding caregivers' depressive symptomatology. Clinical Psychology \& Psychotherapy, 25(1), 59-64. https://doi.org/10.1002/cpp.2116.

Manning, W. D., \& Smock, P. J. (2000). "Swapping" families: Serial parenting and economic support for children. Journal of Marriage and the Family, 62(1), 111-122. https://doi. org/10.1111/j.1741-3737.2000.00111.x.

Masarik, A. S., Conger, R. D., Martin, M. J., Donnellan, M. B., Masyn, K. E., \& Lorenz, F. O. (2013). Romantic relationships in early adulthood: Influences of family, personality, and relationship cognitions. Personal Relationships, 20(2), 356-373. https://doi. org/10.1111/j.1475-6811.2012.01416.x.

Mortelmans, D., Pasteels, I., Bracke, P., Matthijs, K., Van Bavel, J., \& Van Peer, C. (2011). Scheiding in Vlaanderen. Leuven: Acco.

O'Connor, L. E., Berry, J. W., \& Weiss, J. (1999). Interpersonal guilt, shame, and psychological problems. Journal of Social and Clinical Psychology, 18(2), 181-203. https://doi.org/10.1521/ jscp.1999.18.2.181.

Petersen, T. (2004). Analyzing panel data: Fixed- and random-effects models. In M. Hardy \& A. Bryman (Eds.), Handbook of data analysis (pp. 331-345). London: Sage.

Rumpf, H. J., Meyer, C., Hapke, U., \& John, U. (2001). Screening for mental health: Validity of the MHI-5 using DSM-IV Axis I psychiatric disorders as gold standard. Psychiatry Research, 105(3), 243-253. https://doi.org/10.1016/s0165-1781(01)00329-8.

Sayer, L. C., England, P., Allison, P. D., \& Kangas, N. (2011). She left, he left: How employment and satisfaction affect women's and men's decisions to leave marriages. American Journal of Sociology, 116(6), 1982-2018. https://doi.org/10.1086/658173.

Scherpenzeel, A. (2009). Start of the LISS panel: Sample and recruitment of a probability-based Internet panel. Retrieved from Tilburg: 
Scherpenzeel, A., \& Toepoel, V. (2012). Recruiting a probability sample for an online panel: Effects of contact mode, incentives, and information. Public Opinion Quarterly, 76(3), 470490. https://doi.org/10.1093/poq/nfs037.

Tangney, J. P. (1991). Moral affect: The good, the bad, the ugly. Journal of Personality and Social Psychology, 61(4), 598-607. https://doi.org/10.1037//0022-3514.61.4.598.

Tangney, J. P., Stuewig, J., \& Mashek, D. J. (2007). Moral emotions and moral behavior. Annual Review of Psychology, 58, 345-372. https://doi.org/10.1146/annurev.psych.56.091103.070145.

Tilghman-Osborne, C., Cole, D. A., \& Felton, J. W. (2010). Definition and measurement of guilt: Implications for clinical research and practice. Clinical Psychology Review, 30(5), 536-546. https://doi.org/10.1016/j.cpr.2010.03.007.

Waite, L. J., \& Gallagher, M. (2000). The case for marriage: Why married people are happier, healthier, and better off financially. New York: Doubleday.

Wallerstein, J. S., \& Kelly, J. B. (1996). Surviving the breakup: How children and parents cope with divorce. New York: Basic Books.

Watson, D., Clark, L. A., \& Tellegen, A. (1988). Development and validation of brief measures of positive and negative affect - The PANAS scale. Journal of Personality and Social Psychology, 54(6), 1063-1070. https://doi.org/10.1037/0022-3514.54.6.1063.

Webb, M., Heisler, D., Call, S., Chickering, S. A., \& Colburn, T. A. (2007). Shame, guilt, symptoms of depression, and reported history of psychological maltreatment. Child Abuse \& Neglect, 31(11-12), 1143-1153. https://doi.org/10.1016/j.chiabu.2007.09.003.

Williams, K., \& Dunne-Bryant, A. (2006). Divorce and adult psychological well-being: Clarifying the role of gender and child age. Journal of Marriage and Family, 68(5), 1178-1196. https:// doi.org/10.1111/j.1741-3737.2006.00322.x.

Open Access This chapter is licensed under the terms of the Creative Commons Attribution 4.0 International License (http://creativecommons.org/licenses/by/4.0/), which permits use, sharing, adaptation, distribution and reproduction in any medium or format, as long as you give appropriate credit to the original author(s) and the source, provide a link to the Creative Commons license and indicate if changes were made.

The images or other third party material in this chapter are included in the chapter's Creative Commons license, unless indicated otherwise in a credit line to the material. If material is not included in the chapter's Creative Commons license and your intended use is not permitted by statutory regulation or exceeds the permitted use, you will need to obtain permission directly from the copyright holder.

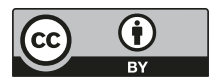

